\title{
Assessment of CGCM 3.1 wind field in the Persian Gulf
}

\author{
Bahareh Kamranzad $\uparrow$, Amir Etemad-Shahidił, Vahid Chegini $\infty$ and Sanaz Hadadpour $\uparrow$
}

†School of Civil Engineering, Iran University of Science and Technology,

Tehran, Iran

kamranzad@iust.ac.ir

sanaz.hadadpour@yahoo.com
†Griffith School of Engineering, Gold

Coast campus, Griffith University QLD

4222

a.etemadshahidi@griffith.edu.au $\infty$ Ocean Engineering and Technology Research Center, Iranian National Institute for Oceanography, Tehran, Iran vahid.chegini@gmail.com

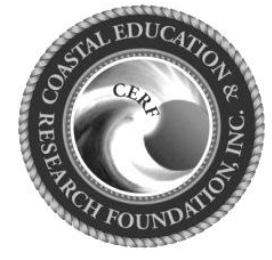

www.cerf-jcr.org

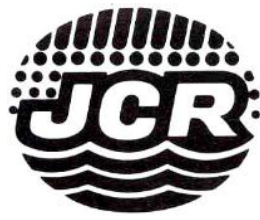

www.JCRonline.org

ABSTRACT

Kamranzad, B., Etemad-Shahidi, A., Chegini, V. and Hadadpour, S., 2013. Assessment of CGCM 3.1 wind field in the Persian Gulf In: Conley, D.C., Masselink, G., Russell, P.E. and O'Hare, T.J. (eds.), Proceedings $12^{\text {th }}$ International Coastal Symposium (Plymouth, England), Journal of Coastal Research, Special Issue No. 65, pp. 249-253, ISSN 07490208 .

\begin{abstract}
Increasing of the greenhouse gases emission causes the climate changes. Therefore, usage of the marine renewable energy resources such as wind and wave energies has been increased during the last decades. Climate variability can change the wind and consequently wave patterns and the available energy amounts. Therefore, assessment of the potential effect of climate change on the wind regime is important. In this paper, wind characteristics obtained from a global climate model (CGCM 3.1) is used for assessing the effects of climate change on the wind regime in the Persian Gulf. CGCM 3.1 results were compared quantitatively with those of ECMWF in the Persian Gulf and the results showed that in comparison to ECMWF, CGCM 3.1 wind speeds are mostly underestimated for both average and maximum values. Dominant wind directions represented by two wind fields are nearly similar except for a point located in Strait of Hormuz. Variations of the annual wind speed in this area were also evaluated until 2100 and time series of annual averages of the wind speeds and statistical analysis indicate a decreasing trend in all points in the domain. Variation of wind speed frequency based on CGCM 3.1 winds was also assessed for different intervals and the results showed that the variations of wind speed frequencies are marginal. Although there is a insignificant reduction in the average wind speed, this can lead to large variations in the wind and wave energies and also extreme values of wave characteristics.
\end{abstract}

\section{ADDITIONAL INDEX WORDS: Climate change, Persian Gulf, CGCM 3.1, ECMWF, wind speed.}

\section{INTRODUCTION}

The earth temperature is increasing due to both natural long term cycles and human-made changes such as increasing the greenhouse gases emission (IPCC, 2007). International panel on climate change (IPCC) represents that the average surface temperature has increases about $0.55^{\circ} \mathrm{C}$ from mid $1970 \mathrm{~s}$ and continue to increasing by $0.16^{\circ} \mathrm{C}$ per decade. Global warming induces pressure change (due to the dependence of air pressure on air temperature) and consequently wind patterns over the earth.

To prevent the negative environmental effects and due to the limitations in fossil fuels, usage of the marine renewable energy resources such as wind and wave energies, instead of fossil fuels, has been increased during the last decades. In addition, knowledge of extreme winds and waves is required for marine industries. Climate variability can change the wind pattern and consequently its magnitude and frequency of occurrence. Therefore, assessment of the potential effect of climate change on variation of the wind regime is essential.

The effect of climate change on wind patterns has been assessed in studies such as Deepthi and Deo (2010), Segal et al. (2001), Pereira de Lucena et al. (2010), Breslow and Sailor (2002) and Pryor et al. (2004). In most of these studies, increasing or decreasing of wind speed and wind power are estimated in different areas in the world using global or regional climate models. Global Climate Models (GCMs) simulate the response of

DOI: 10.2112/SI65-043.1 received 07 December 2012; accepted 06 March 2013

(c) Coastal Education \& Research Foundation 2013 the global climate system to the increasing greenhouse gases emission. Climate change scenarios from GCMs such as Canadian Coupled Global Climate Model (CGCM) (e.g. Flato et al., 2000), coupled global Hadley Centre Climate Model (HadCM) (Gordon et al., 2000; Pope et al., 2000) and ARPEGE-Climate atmospheric GCM (Gibelin and Déqué, 2003) are usually appropriate for assessing the general trend of the wind characteristics.

Wind parameters variation during the long term period are assessed in this study for the Persian Gulf. For this purpose, wind characteristics obtained from a global climate model (CGCM 3.1) are used for assessing the effect of climate change on wind regime. Since CGCM 3.1 is a low resolution model, its results were controlled by comparing them with a local model. The local model selected for this purpose was ECMWF which has showed acceptable consistency with the measured values and produced accurate wave field (Moeini et al., 2012).

\section{METHODS}

\section{Study Area and Data Resources}

Assessment of the effect of climate change on wind pattern was carried out in the Persian Gulf (Figure 1). Persian Gulf is located in south of Iran and it is one of the semi-enclosed water bodies in the world and is an important area because of its strategic location and natural resources of oil and gas. Marine transportation has made the Persian Gulf very important as well. Therefore, knowing the variation of wind parameters during the long time caused by climate change is necessary in this area. 


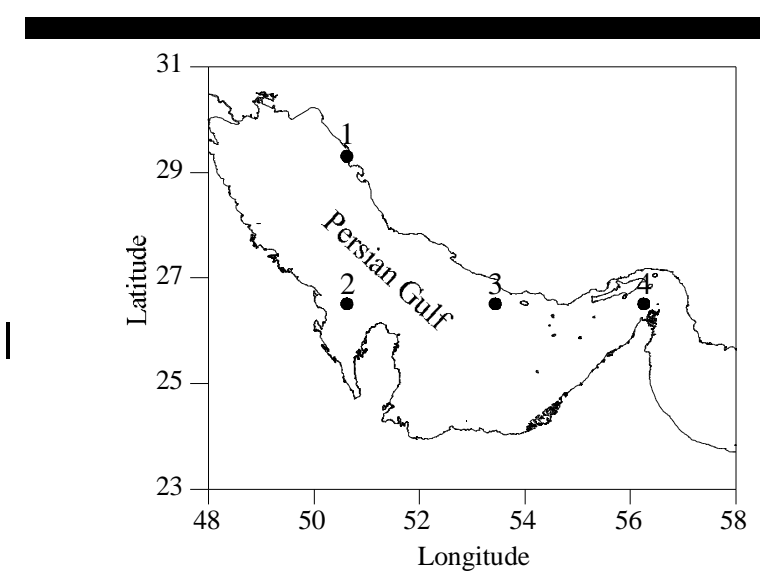

Figure 1. Study area.

The used Global climate model (GCM) was the third generation Coupled Global Climate Model (CGCM 3.1) version T63

developed by Canadian Centre for Climate Modelling and Analysis (CCCma). The initial version of CGCM3 was developed and ran on a NEC SX/6 vector supercomputer and CGCM 3.1 was run on a new distributed memory IBM computer system. CGCM 3.1 uses both some oceanic and atmospheric components. The Coupled Global Climate Model uses greenhouse gas forcing change as input. The basic structure of the Atmospheric General Circulation Model is similar to that of the spectral forecast model of Daley et al. (1976). In addition, some improvements were carried out for implementing the spectral algorithms and important additional physical processes were also included (Environment Canada).

In the Atmospheric General Circulation Model, the equations governing horizontal motion are written in terms of vorticity and divergence of the horizontal wind, the thermodynamic equation written in terms of a function of geopotential height, the moisture equation written in terms of dew-point depression and the surface pressure equation. Temperature is also determined diagnostically from the geopotential with the hydrostatic equation and the vertical motion variable is determined from the mass continuity equation with the hydrostatic equation and the vertical motion variable is determined from the mass continuity equation (Environment Canada).

The spatial and temporal resolutions were about 2.8 degree in latitude and longitude and daily average, respectively. This model was used to produce the data for the present (control) period from 1850 to 2000 (named 20C3M) and also for the future in three emission scenarios (A2, B1 and A1B) of the IPCC from 2001 to 2100.

Local wind field was obtained from the European Centre for Medium-Range Weather Forecasts (ECMWF). This wind contains the wind vector in 10 meters from the sea level with 0.5 degree and 6-hourly spatial and temporal resolutions, respectively. This model is used widely for wave modeling and produces acceptable results (e.g. Moeini et al., 2010). Winds obtained from buoy measurements or synoptic stations are the alternatives for validation of CGCM 3.1 wind regime. However, the buoy measurements are recorded in limited time intervals and are not a good source for long term assessment in comparison with ECMWF wind data. Synoptic data are also measured on the land and they are not an appropriate option for evaluating the sea winds. Therefore, considering the benefits of comprising the long term data_over the sea surface, ECMWF was selected for assessment of CGCM 3.1 in the Persian Gulf.

\section{RESULTS}

\section{Evaluation of CGCM 3.1 in Persian Gulf}

In order to evaluate the CGCM 3.1 results in the Persian Gulf, it was compared with ECMWF wind field. This comparison was carried out in four points in the Persian Gulf (Figure 1). some of these points are located near the coastal areas where numerical models have limited ability_to produce the reliable data in coastal areas with complicated orography. However, these points were selected based on the spatial resolution of CGCM 3.1 where the data are available in the domain. Two wind fields were compared quantitatively in these points from 1980 to 2000 . Although the wind resolutions were different, the comparison was carried out for assessing the quality of CGCM 3.1 in the mentioned points. Further assessment will be done for localizing the CGCM 3.1 using interpolation and downscaling approaches. Therefore, the annual averages and maximums of wind speed were obtained and shown in Table 1. According to this table, in comparison to ECMWF, CGCM 3.1 wind speeds are mostly underestimated in both average and maximum values. Therefore, CGCM 3.1 wind speeds require modification before using them as an input for wave modeling or any usage of the wind field. At first, existing bias between the average wind speeds (for example monthly averages) obtained from two sources should be minimized. This can be done using a simple regression or any complicated and more accurate approach such as neural network (Sailor et al., 2000; Kamranzad et al., 2011).

For assessing the quality of the CGCM 3.1, wind directions of the two sources were compared using wind roses. Wind roses are

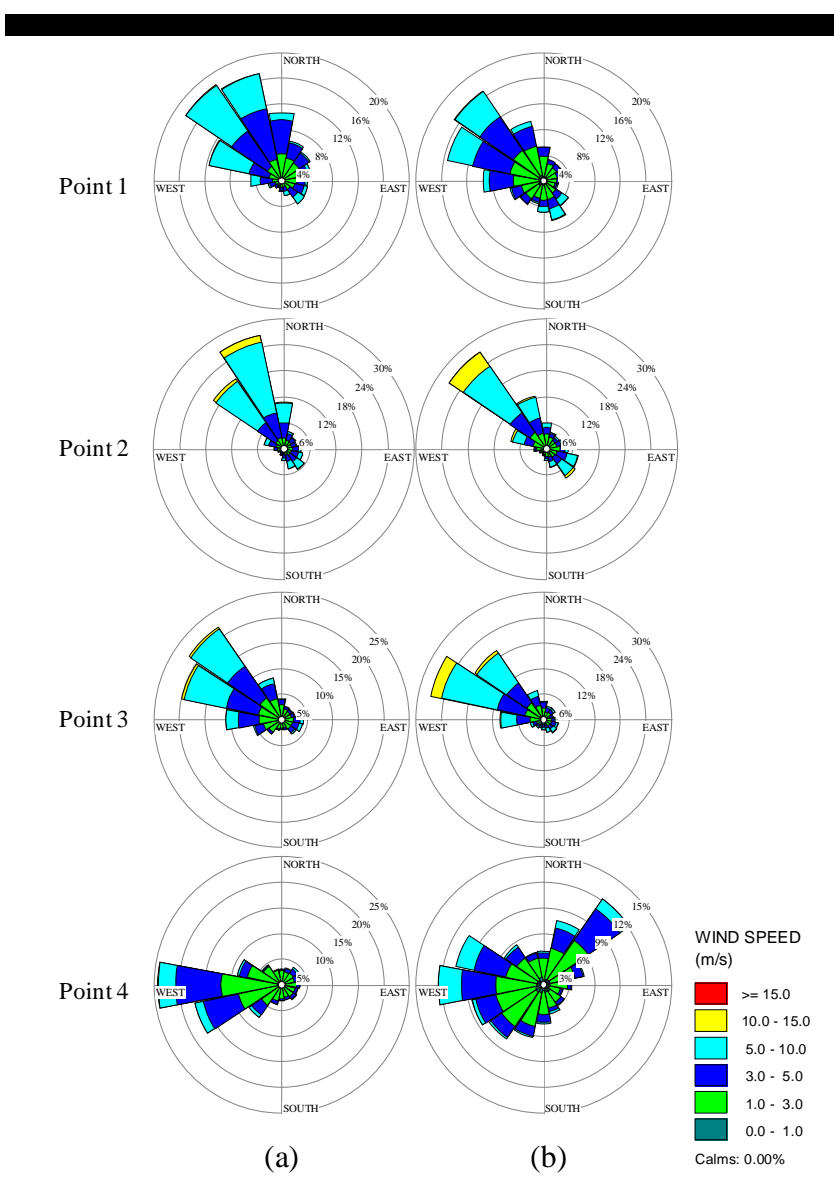

Figure 2. Wind roses in four points (a) ECMWF and (b) CGCM 3.1 . 
Table 1. Wind speed statistics of two models.

\begin{tabular}{cccc}
\hline \hline Point & $\begin{array}{c}\text { Statistical index } \\
(\mathbf{m} / \mathbf{s})\end{array}$ & ECMWF & 20C3M \\
\hline \multirow{4}{*}{$\mathbf{1}$} & Min & 0.02 & 0.04 \\
& Ave & 3.89 & 3.07 \\
& Max & 13.25 & 12.31 \\
& StDev & 1.88 & 1.89 \\
$\mathbf{2}$ & Min & 0.02 & 0.06 \\
& Ave & 4.75 & 4.39 \\
& Max & 15.36 & 15.19 \\
& StDev & 2.52 & 2.95 \\
$\mathbf{3}$ & Min & 0.02 & 0.02 \\
& Ave & 3.60 & 4.39 \\
& Max & 14.34 & 14.91 \\
& StDev & 2.16 & 2.72 \\
$\mathbf{4}$ & Min & 0.02 & 0.01 \\
& Ave & 2.59 & 2.62 \\
& Max & 12.57 & 10.90 \\
& StDev & 1.50 & 1.61
\end{tabular}

shown in Figure 2. This figure indicates that the dominant wind directions represented by two wind fields (i.e. CGCM 3.1 and ECMWF) are nearly similar except for the point located in Strait of Hormuz (point 4). In this point, the orography condition is complicated and the wind pattern is highly affected by surrounding lands and numerical wind models perform weak in such areas.

\section{Impact of climate change on the wind resource in Persian Gulf}

Variations of the annual wind speed was also evaluated from 1960 to 2100 in the Persian Gulf using control wind speeds and A2, B1 and A1B emission scenarios obtained from CGCM 3.1 wind field. For this purpose, annual averages of CGCM 3.1 wind speeds were calculated and the variation was assessed using time series and statistical analysis. The trendlines shown in Figure 3 have been fitted to wind speeds derived from A2 scenario. Time series of annual averages of the wind speeds (Figure 3 ) indicate a global decreasing trend in all four points of the domain for all the future scenarios.

For quantitatively assessment of the variations, statistical analysis was also carried out for 25-yearly periods from 1976 to 2100 (i.e. 1976-2000, 2001-2025, 2026-2050, 2051-2075 and 2076-2100). The impact of climate change on the wind regime near the Iranian (northern) coasts was of interest in this research. Point 1 is located near the coastal area and point 4 is located in the Strait of Hormuz, where the orography condition caused a complicated wind pattern. Therefore, point 3 was selected as the best station for assessing the wind regime. Table 2 indicates the wind speed variations during the long term period at point 3 .

The statistical analysis showed that all scenarios predict a reduction in all 25-yeraly average wind speed values in comparison with the previous periods. The decreasing rates of the 25-yearly average wind speeds using A2 and B1 scenarios are the maximum and minimum values, respectively. The maximum reduction rate of the 25-yeraly average wind speed is about $4.6 \%$ according to A2 scenario. Since a minor variation in the wind speed may result in major variations in wave characteristics, the $4.6 \%$ decrease in the wind speed, leads to a large reduction of the wind and wave energies and also extreme wave characteristics values.

Variation of wind speed frequency for different intervals during the long time was also assessed using CGCM 3.1 wind field. For

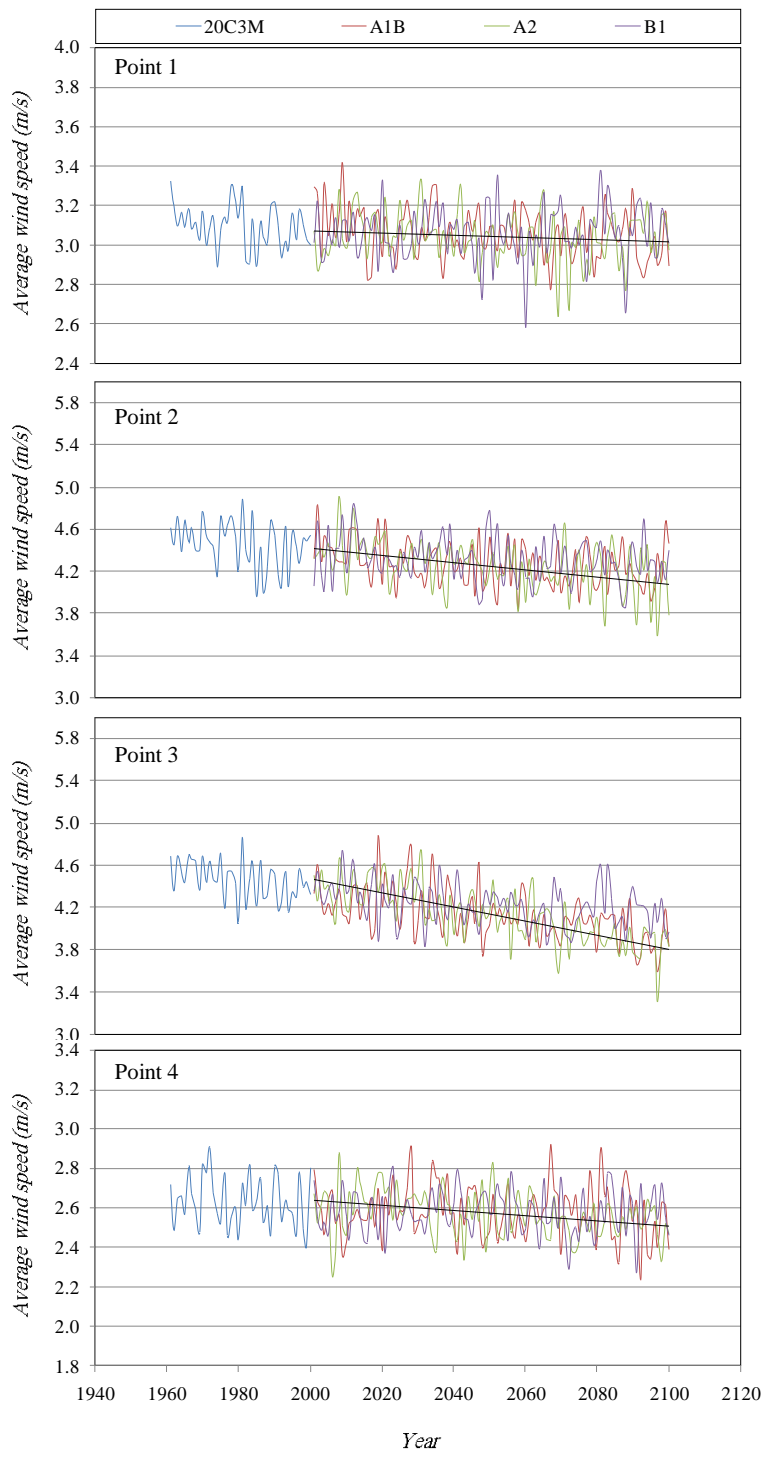

Figure 3. Wind speed variations in four points using different scenarios.

this purpose, frequencies of wind speeds were obtained for each interval (Figure 4). Calculations for the control period and future scenarios were carried out for 1980 to 2000 and 2080 to 2100 , respectively. Figure 4 illustrates that at points 2 and 3 which are located in the offshore, frequency of maximum wind speeds are

more than those of points 1 and 4 . This can be due to the effect of orography and large scale obstacles such as mountains surrounding the area that reduce the maximum wind speed in coastal areas. In addition, emission scenarios of A2 and A1B show similar frequencies at points 1 and 4 while $\mathrm{A} 2$ scenario represents higher frequency than A1B for wind speeds of less than $3 \mathrm{~m} / \mathrm{s}$ at points 2 and 3. Moreover, A2 and B1 scenarios indicate higher frequency in lower and higher wind speeds, respectively.

Generally, in all points and all intervals, frequency of the wind speed obtained from B1 scenario is the closest to the frequency of control wind, i.e. 1980 to 2000. This means that the wind speeds of B1 scenario contain the least variation of the future in comparison with the past condition. 
Table 2. Wind speed variation at point 3 for different scenarios.

\begin{tabular}{cccc}
\hline \multicolumn{4}{c}{ Using data obtained from A2 scenario } \\
\hline Period & $\begin{array}{c}\text { Average } \\
\text { wind speed } \\
(\mathbf{m} / \mathbf{s})\end{array}$ & $\begin{array}{c}\text { Wind speed } \\
\text { variation } \\
(\mathbf{m} / \mathbf{s})\end{array}$ & $\begin{array}{c}\text { Wind speed } \\
\text { variation }(\%)\end{array}$ \\
\hline $1976-2000$ & 4.399 & & \\
$2001-2025$ & 4.386 & -0.013 & -0.30 \\
$2026-2050$ & 4.215 & -0.171 & -3.90 \\
$2051-2075$ & 4.062 & -0.153 & -3.60 \\
$2076-2100$ & 3.877 & -0.185 & -4.60 \\
\multicolumn{5}{c}{ Using data obtained from B1 scenario } \\
$1976-2000$ & 4.399 & \multicolumn{3}{c}{} \\
$2001-2025$ & 4.323 & -0.076 & -1.70 \\
$2026-2050$ & 4.278 & -0.045 & -1.10 \\
$2051-2075$ & 4.151 & -0.127 & -3.00 \\
$2076-2100$ & 4.192 & 0.041 & 1.00 \\
\multicolumn{5}{c}{ Using data obtained from A1B scenario } \\
$1976-2000$ & 4.399 & \multicolumn{3}{c}{} \\
$2001-2025$ & 4.274 & -0.125 & -2.80 \\
$2026-2050$ & 4.201 & -0.073 & -1.70 \\
$2051-2075$ & 4.086 & -0.115 & -2.70 \\
$2076-2100$ & 3.967 & -0.119 & -2.90
\end{tabular}

\section{CONCLUSION}

Wind characteristics obtained from CGCM 3.1 was used for assessing the effect of climate change on wind regime in the Persian Gulf. For this purpose, CGCM 3.1 results were compared with those of ECMWF at four points and the results showed that

CGCM 3.1 wind speeds are underestimated and a regression or other complicated approaches are required for modifying CGCM 3.1 to reduce the bias.

Directional analysis using wind roses indicated a similar dominant direction for two wind sources except for a point located in Strait of Hormuz. This was mainly due to the complicated condition and orography pattern in this area. The variations of the annual wind speed were also investigated until the year 2100. For this purpose, time series of annual averages of the wind speeds were plotted and statistical analysis was carried out. Results indicated a decreasing trend in all points of the domain.

Moreover, Variation of wind speed frequency based on CGCM 3.1 winds was also assessed for different intervals for control period (1980 to 2000) and future period (2080-2100) using the emission scenarios of A2, B1 and A1B. The results showed that the variations of wind speed frequencies are negligible and $\mathrm{A} 2$ and B1 scenarios indicate higher frequency in lower and higher wind speeds, respectively.

In addition, the wind speeds of B1 scenario contain the least variation in the future in comparison with the past condition. Although there is a low reduction in average wind speed, this may lead to large variations in wind and wave energies and also extreme wave characteristics values.

\section{LITERATURE CITED}

Breslow, P.B. and Sailor, D.J., 2002. Vulnerability of wind power resources to climate change in the continental United States. Renewable Energy, 27, 585-598.
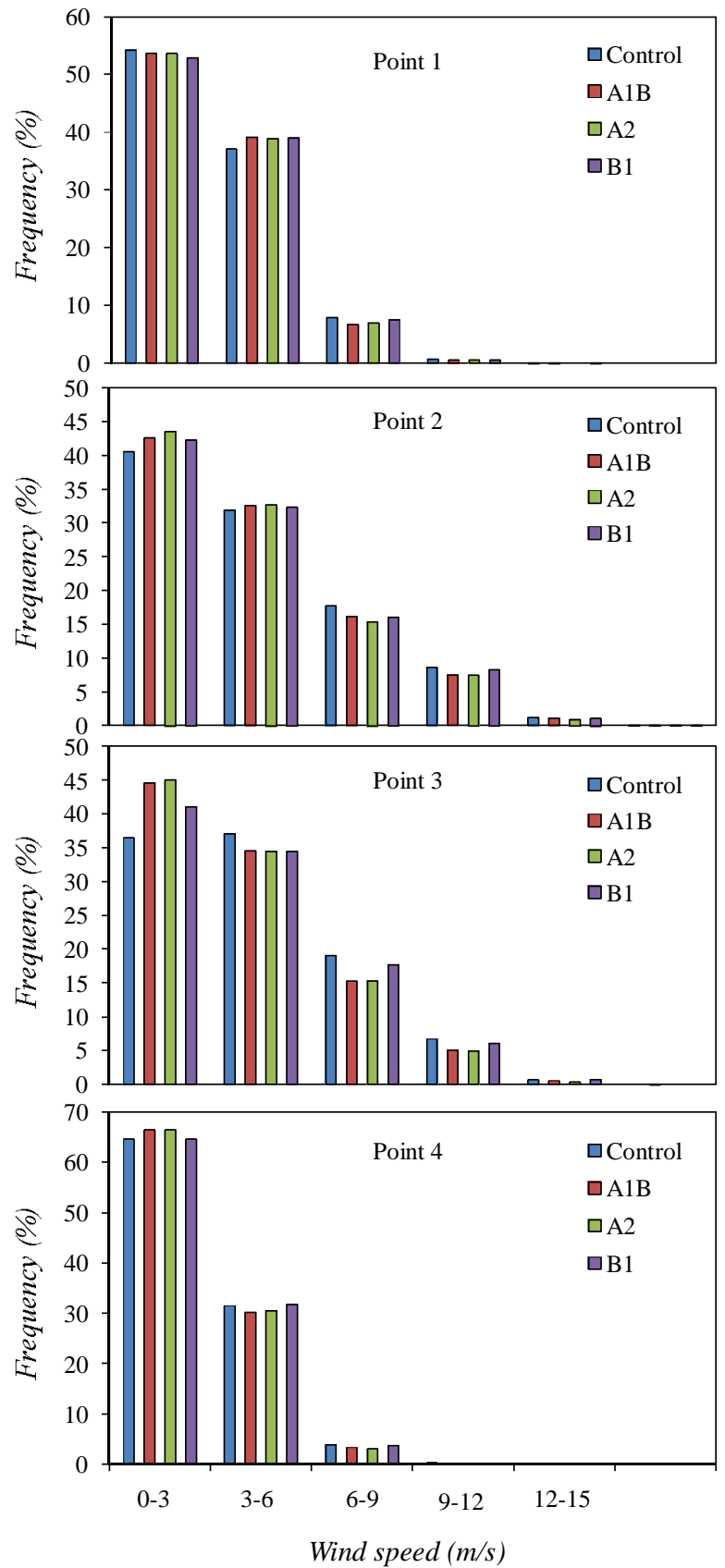

Figure 4. Wind speed frequency for four points, different scenarios.

Daley, R., Girad, C., Henderson, J. and Simmonds, I., 1976. Short term forecasting with a muti-level spectral primitive equation model. Part I - Model formulation. Atmosphere, 14, 98-116.

Deepthi, R. and Deo, M.C., 2010. Effect of climate change on design wind at the Indian offshore locations. Ocean Engineering, 37, 1061-1069.

Environment Canda, http://www.ec.gc.ca/ccmac-cccma.

Flato, G.M., Boer, G.J., Lee, W.G., McFarlane, N.A., Ramsden, D., Reader, M.C. and Weaver, A.J., 2000. The Canadian centre for climate modeling and analysis global coupled model and its climate. Climate Dynamics, 16, 451-467. 
Gibelin, A. and Déqué, M., 2003. Anthropogenic climate change over the Mediterranean region simulated by a global variable resolution model. Climate Dynamics, 20, 327-339.

Gordon, C., Cooper, C., Senior, C.A., Banks, H., Gregory, J.M., Johns, T.C., Mitchell, J.F.B. and Wood, R.A., 2000. The simulation of SST, sea ice extents and ocean heat transports in a version of the Hadley Centre coupled model without flux adjustments. Climate Dynamics, 16, 147-168.

IPCC, 2000. IPCC special report, emission scenarios. A Special Report of IPCC Working Group III.

Kamranzad, B., Etemad-Shahidi, A. and Kazeminezhad, M., 2011. Wave height forecasting in Dayyer, the Persian Gulf. Ocean Engineering, 38, 248-255.

Moeini, M.H., Etemad-Shahidi, A. and Chegini, V., 2010. Wave modeling and extreme value analysis off the northern coast of the Persian Gulf. Applied Ocean Research, 32, 209-218.

Moeini, M.H., Etemad-Shahidi, A., Chegini, V. and Rahmani, I., 2012. Wave data assimilation using a hybrid approach in the Persian Gulf. Ocean Dynamics, 62, 785-797.

Pereira de Lucena, A.F., Szklo, A.S., Schaeffer, R. and Dutra, R.M., 2010. The vulnerability of wind power to climate change in Brazil. Renewable Energy, 35, 904-912.

Pope, V.D., Gallani, M.L., Rowntree, P.R. and Stratton, R.A., 2000. The impact of new physical parametrizations in the Hadley Centre climate model HadAM3. Climate Dynamics, 16, 123-146.

Pryor, S.C., Barthelmie, R.J. and Schoof, J.T., 2004. Historical and prognostic changes in a normal wind year: A case study from the Baltic. In: Proceedings. Delft: Delft University of Technology, 336-345.

Sailor, D.J., Hu, T., Li, X. and Rosen, J.N., 2000. A neural network approach to local downscaling of GCM output for assessing wind power implications of climate change. Renewable Energy, 19, 359-378.

Segal, M., Pan, Z., Arritt, R.W. and Takle, E.S., 2001. On the potential change in wind power over the US due to increases of atmospheric greenhouse gases. Renewable Energy, 24(2): 235243. 